\title{
An Ocullar Photometric Method for Radiation Biodosimetry in Patients Following Whole Body Irradiation
}

Julian Down ${ }^{1}$, Daniel Reiley ${ }^{2}$, Mitchell Kamrava ${ }^{3}$, Patrick Kupelian ${ }^{4}$, Amanuel Legesse ${ }^{2}$, Herman L. Lelie ${ }^{2}$, James Axtelle ${ }^{2}$, Thomas J. Smith ${ }^{5}$, William H. McBride ${ }^{4}$, Naresh Menon ${ }^{2}$

1. ChromoLogic, LLC 2. ChromoLogic LLC, Pasadena, CA 3. Department of Radiation Oncology, UCLA Medical Center 4. Dept. Radiation Oncology, UCLA, Los Angeles, CA 5. Auritec Pharmaceuticals, Pasadena, CA

$\square$ Corresponding author: Julian Down, jdown@chromologic.com

Disclosures can be found in Additional Information at the end of the article

\section{Abstract}

In order to address mass casualty situations in the event of radiation exposure from nuclear attacks or accidents, there is an urgent and unmet need for point-of-care (POC) diagnostic devices for rapid assessment of absorbed radiation dose. Patients receiving whole body irradiation (WBI), which is often included as part of the preparative regimen prior to hematopoietic stem cell transplantation (HSCT), can be used as subjects for evaluation of radiation biodosimeters that may be of use in a nuclear event as well as in radiation therapy. The level of WBI exposure in patients is frequently associated with treatment-related complications to multiple tissues and involves individual variations in radiosensitivity. Thus, early and predictive indicators of individual outcomes of radiation exposure would allow preemptive clinical management before the onset of tissue injury. To address these critical needs, we are developing an ocular dosimeter (OCDOS) that noninvasively assesses radiation-induced damage by measuring light scattered by proteins present in the aqueous humor (AH) the eye. Therefore, we initiated a clinical study to assess the potential of OCDOS in patients before and during a fractionated course of WBI conditioning therapy prior to HSCT. Early results in three patients show a clear difference in light scattering properties of the AH from measurements taken before and after irradiation that persists for several days into treatment. This preliminary study provides proof of principle that this non-invasive and POC device can assess doserelated changes in proteins in patients receiving WBI and is suitable for high throughput, triage assessment of individuals exposed in a mass casualty scenario of a nuclear event.

Received 12/03/2012

Review began 12/06/2012

Published 04/15/2013

๑) Copyright 2013

Down et al. This is an open access article distributed under the terms of the Creative Commons Attribution License CC-BY 3.0., which permits unrestricted use, distribution, and reproduction in any medium, provided the original author and source are credited.
Categories: Internal Medicine, Radiation Oncology, Miscellaneous Keywords: ocular, photometry, whole body irradiation, radiation biodosimetry, radiosensitivity, aqueous humor

\section{Introduction}

Current biodosimetric approaches for estimating radiation dose and anticipating the effects of exposure from nuclear events often require tissue collection, sampling and laboratory-intensive methodologies with results typically not available for several days [1]. It is also well-recognized that there is a wide inter-patient variation in normal tissue reactions to radiotherapy and identifying patients likely to develop severe reactions would be a considerable advance by allowing dose to be individually tailored [2-4]. Patients receiving WBI as part of the conditioning regimen before HSCT for treatment of disseminated malignancies are expected to have some toxicities attributed to systemic radiation exposure, including early effects on the 
immunohematopoietic system, oral mucosa, and gastrointestinal epithelium as well as delayed complications in tissues, such as lung and kidney, with a subset having serious complications [5]. The same radiation toxicities are of concern in a mass casualty scenario following nuclear incidents. These patients are therefore useful for testing POC radiation biodosimeters that might be of use in the clinic and for rapid triage after nuclear events in allocating subjects for appropriate treatment with potential mitigating therapies $[1,6]$.

The current clinical study describes how a non-invasive ocular dosimeter (OCDOS) is capable of quantitatively and objectively measuring light-scattering changes in the anterior chamber of the eye as a result of WBI exposure and has the potential to identify sensitive patients in need of further medical management in both radiation therapy and nuclear events.

\section{Materials And Methods}

\section{Patient treatment}

The WBI regimen consists of a hyperfractionated course of 1.5 or 1.65 Gy doses given twice per day over four days, accumulating to a total dose of 12 or 13.2 Gy delivered by a 6 MV linear accelerator (Siemens Avant Guard) at 10-12 cGy/min (Figure 1). Additional anti-cancer and immune suppressive chemotherapy was delivered on the days after the completion of WBI. Patient P01 was a 53-year-old female at treatment presenting with relapsed acute myeloid leukemia who received $60 \mathrm{mg} / \mathrm{kg}$ cyclophosphamide on days two and three and $25 \mathrm{mg} / \mathrm{m} 2$ fludarabine on days one, two, and three after 13.2 Gy WBI, also as part of the conditioning regimen prior to allogeneic HSCT. Patient P02 was a 54-year-old female with B-cell acute lymphocytic leukemia who received $60 \mathrm{mg} / \mathrm{kg}$ cyclophosphamide on days one and two after 12 Gy WBI, followed by allogeneic HSCT. Patient P03 was a 42-year-old male with relapsed refractory Hodgkin's lymphoma who received etoposide on day one and $60 \mathrm{mg} / \mathrm{kg}$ cyclophosphamide on day three after 12 Gy WBI, followed by autologous HSCT. All patients were screened for any pre-existing known eye conditions, including glaucoma, cataract, or other conditions that may result in ocular inflammation.

\section{Photometric measurements}

This is a longitudinal feasibility study of a novel non-invasive device in assessing radiation dose exposure in humans (http://clinicaltrials.gov/ct2/show/NCT01640236) and was approved by the Institutional Review Board (IRB) of the University of California, Los Angeles (UCLA). The current OCDOS instrument analyzes the back-scattered light at multiple angles and wavelengths from the anterior chamber of the eye to allow for simultaneous measure of average AH molecular weight and concentration of proteins. This concept for measuring protein concentration and average molecular weight in an aqueous medium is based on the wellestablished Zimms formulism to the classical Rayleigh scattering technique [7]. The theory associated with multi-angle scattering analysis for measuring concentration of specific proteins (average mass and radius) is according to the following equation.

Where: 1) $R(\theta, \lambda)$ is the intensity of scattered light measured at a given wavelength $(\lambda)$ and scattering angle $(\theta), 2) \mathrm{c}$ is the sample concentration, 3) $\mathrm{M}$ is the molecular weight, 4) $\mathrm{A}_{2}$ is the second viral coefficient (typically considered negligible when concentrations are less than $0.1 \mathrm{mg} / \mathrm{ml}), 5) \mathrm{K}^{*}$ is an optical parameter equal to $\left.4 \pi^{2} \mathrm{n}^{2}(\mathrm{dn} / \mathrm{dc})^{2} /\left(\lambda^{4} \mathrm{~N}_{\mathrm{A}}\right), 6\right) \mathrm{n}$ is the solvent refractive index and $\mathrm{dn} / \mathrm{dc}$ is the refractive index increment, 7) $\mathrm{N}_{\mathrm{A}}$ is Avogadro's number.

$1 / \mathrm{P}(\theta, \lambda)=1+\left(16 \pi^{2} / 3 \lambda^{2}\right)<\mathrm{r}_{\mathrm{g}}{ }^{2}>\sin ^{2}(\theta / 2)+$, is a Taylor expansion for the angular dependence of the scattered light where $r_{g}$ is the average radius and $\theta$ is the scattered light. 


\section{Cureus}

The anterior chamber of the eye was illuminated by three ISO 15004-2:2007 compliant visable illumination sources. The returned light, consisting mostly of back-scattered light from the aqueous humor is captured using a photo detector (PD) placed about $50 \mathrm{~cm}$ from the eye (Figure 2). The geometrical arrangement of the optics minimizes backscatter from the lens and cornea. The data from the PD was processed to compute a parameter that is proportional to the average molecular weight of the proteins present in the AH by applying the Zimms Scattering formulism. The OCDOS measurements were performed on the day before and within 20 minutes after the first WBI dose and following accumulated radiation doses at days two, three and four (Figure 1).

12 or 13.2 Gy WBI - Total Accumulated Dose

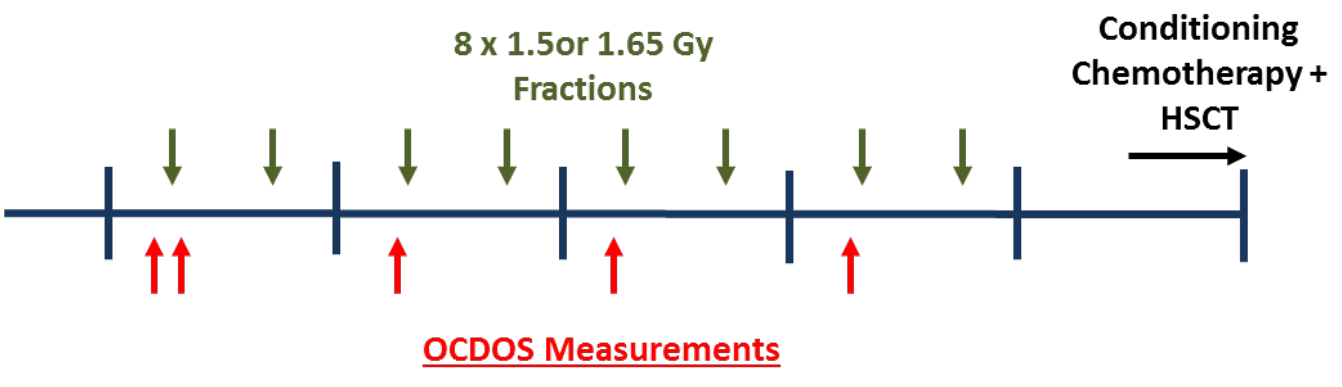

1

2

3

4

DAY OF WBI

\section{FIGURE 1: OCDOS measurements in relation to WBI}

\section{treatments}

OCDOS measurements in relation to WBI treatments. This corresponded to 0 Gy (pre-WBI) and post-WBI after having received the first fractionated 1.5 or 1.65 Gy dose on day 1,3 or $3.3 \mathrm{~Gy}$ cumulative (day 2), 6 or 6.6 Gy cumulative (day 3) and 9 or 9.9 Gy cumulative (day 4) doses.

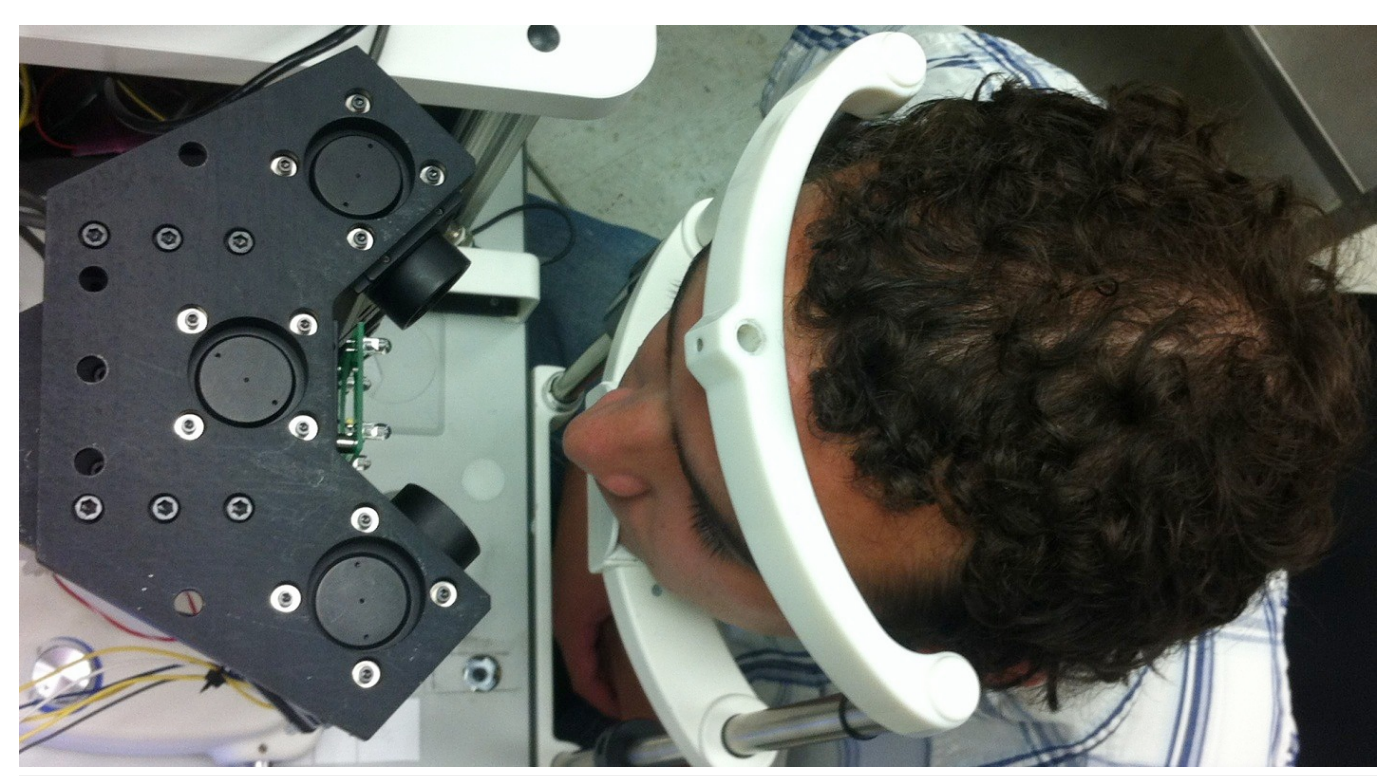

FIGURE 2: OCDOS device allowing non-invasive and noncontact assessment of light-scattering properties of the $\mathrm{AH}$ 
OCDOS device allowing non-invasive and non-contact assessment of light-scattering properties of the $\mathrm{AH}$. Light from three eye-safe LEDs is projected into the anterior chamber of the eye. The light that is scattered within the $\mathrm{AH}$ is collected and then analyzed using spectral analysis methods.

\section{Results}

The OCDOS instrument was calibrated using an in vitro eye model (Figure 3). This was performed by measuring the response of the OCDOS system to varying proportions of the two most abundant proteins in the AH: albumin $(69 \mathrm{kDa})$ and immunoglobulin $\mathrm{G}(\mathrm{IgG})(150 \mathrm{kDa})$ at equal concentrations $(0.2 \mathrm{mg} / \mathrm{ml})$ in a synthetic aqueous humor buffer solution [8]. The data indicates the ability of the OCDOS system to identify proteins by their average molecular weight and average radius at relatively small concentrations. Figure 4 presents the percent change in the OCDOS value (correlated to the average molecular weight of the AH proteome) as a function of time and cumulated dose during WBI treatment for the three patients. It demonstrates that OCDOS can distinguish significant light-scattering changes in the AH attributed to an increase in protein concentration and/or average protein molecular weight and radius, even after the first dose of 1.5 or $1.65 \mathrm{~Gy}$. Interestingly, the patients differ with respect to the maximal OCDOS response achieved at the higher radiation doses pointing to the possibility that this may be used to distinguish individuals with variations in radiation susceptibility. As other clinical variables might also influence the magnitude of the response, it will be important in the future to determine how well the OCDOS readings correlate with other measures of radiation damage and clinical symptoms.

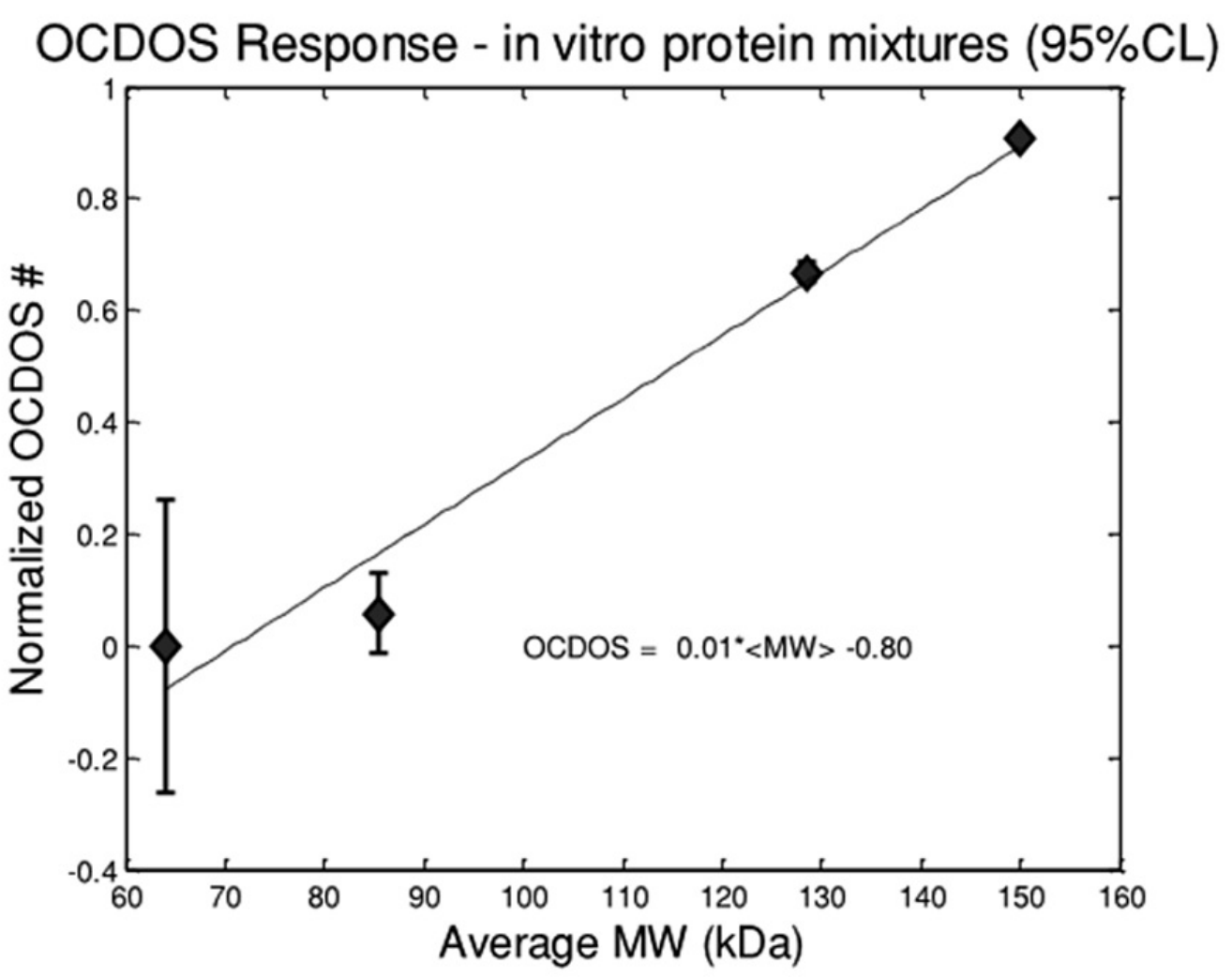

\section{FIGURE 3: The OCDOS system was calibrated with an in-vitro eye model}

The OCDOS system was calibrated with an in-vitro eye model. Synthetic aqueous humor was prepared with mixtures of the two most abundant proteins in the $\mathrm{AH}$, albumin and IgG such that 


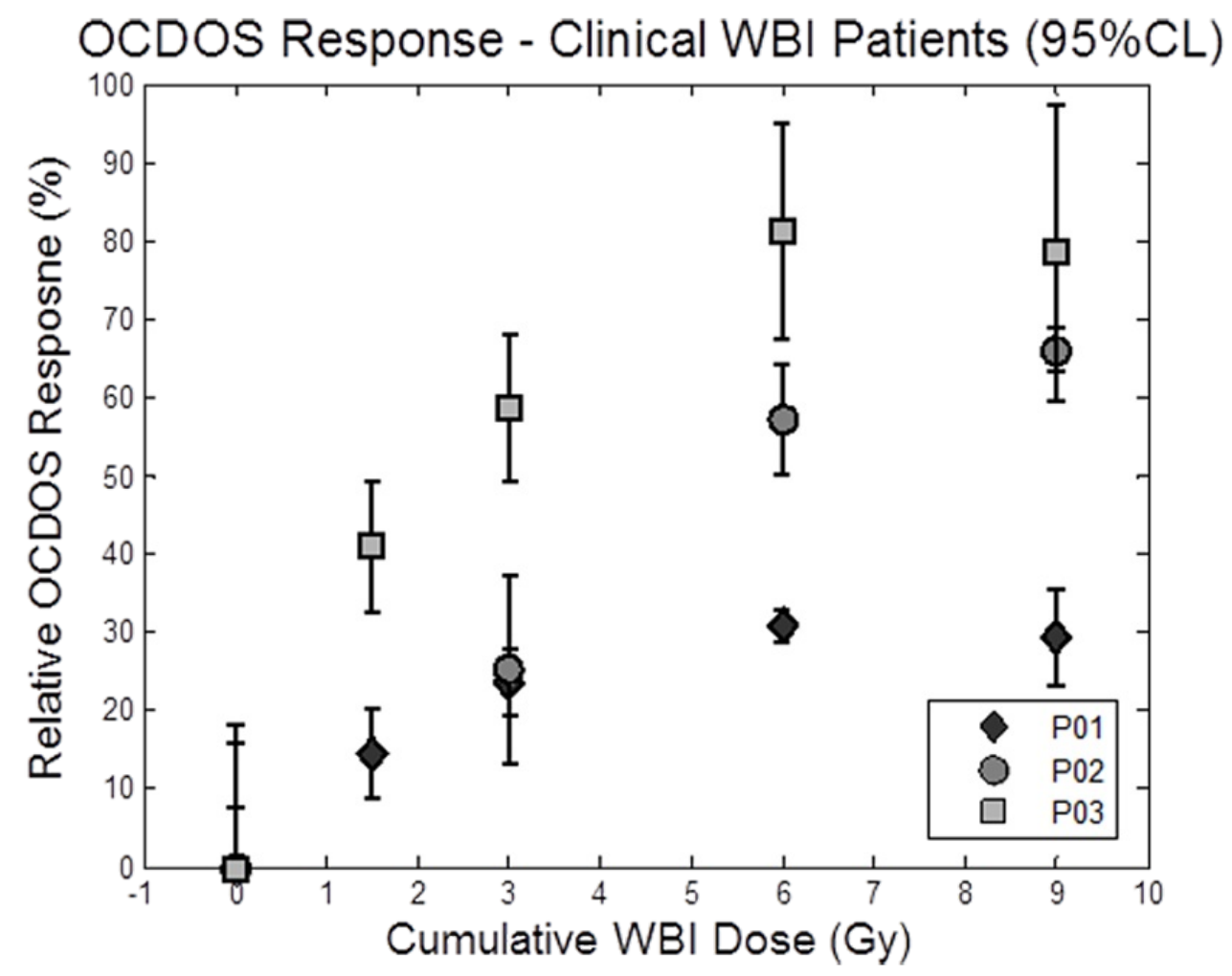

\section{FIGURE 4: OCDOS response measured in three different patients}

OCDOS response measured in three different patients as percent change $( \pm 95 \% \mathrm{CL})$ in the blue-green slope as shown in Figure 3 to show a radiation dose-dependent effect from an increase in the average molecular weight and radius of proteins present in the $\mathrm{AH}$

\section{Discussion}

These preliminary results show, for the first time, dose-related changes in the composition of the $\mathrm{AH}$ in the anterior chamber of the human eye attributed to exposure to ionizing radiation as detected by light scattering properties. The alterations were without any signs of visual impairment and patients were selected to have no prior history of eye complications. Other factors, such as disease status and prior chemotherapy, cannot be excluded as contributing to the magnitude of these AH changes but this will require further study.

The mechanisms that account for radiation-induced changes in AH light-scattering have yet to be fully resolved. The protein constituents of the $\mathrm{AH}$ are tightly regulated by the blood-eye barrier (BEB) formed by the non-pigmented layer of the epithelium of the ciliary body and the endothelium of the blood vessels of the uvea [9]. Disruption of the BEB by irradiation can result in an apparent increase in concentration of proteins present in the AH [10], although studies are limited to localized irradiation of the eye of rabbits. Such responses appear to vary among species [11]. Other possible radiation-induced changes include alteration in the relative contribution of albumin and immunogobulin $G(\operatorname{IgG})$, the two most abundant proteins in the 
AH [12-13], which have over a two-fold difference in molecular weight. Their quantitation in $\mathrm{AH}$ remains challenging due to the low protein content and the relatively small volume of $\mathrm{AH}$ in experimental animals. For humans, extraction of AH through paracentesis is impossible for ethical reasons. Our own analysis of the AH through mass-spectroscopy in irradiated nonhuman primates shows a dose-related change in proteins associated with inflammation, immunity, and redox fluctuations that are well-known markers of acute radiation responses [14-15]. Changes in protein composition in the AH may also reflect a drop in serum albumin as documented in experimental studies after WBI, perhaps related to early vascular leakage in multiple tissues [16-18] with an associated change in the composition of the AH.

\section{Conclusions}

In conclusion, we have found that the regular daily monitoring of AH protein composition using the OCDOS device during the course of radiotherapy, and after each accumulated radiation dose, yields valuable dose-response relationships for each individual patient. Such a rapid and non-invasive approach has advantages over other predictive bioassays that require reagents or body fluid samples. The ability of OCDOS measurements to distinguish changes after the lowest radiation dose of 1.5 or 1.65 Gy supports its potential to recognize and manage individuals at risk of developing radiation toxicities in a nuclear event. Of additional interest are the divergent OCDOS responses seen at higher doses among the three patients so far studied. Whether such variations beyond the actual radiation doses received will enable individuals with intrinsic genetically determined differences in radiosensitivity to be identified and stratified early during the course of radiotherapy warrants further investigation for a larger cohort of patients and with correlations of subsequent radiation-related clinical responses.

\section{Additional Information}

\section{Disclosures}

Human subjects: Consent was obtained by all participants in this study. The Institutional Review Board (IRB) of the University of California, Los Angeles (UCLA) issued approval N/A. Animal subjects: All authors have confirmed that this study did not involve animal subjects or tissue. Conflicts of interest: In compliance with the ICMJE uniform disclosure form, all authors declare the following: Payment/services info: All authors have declared that no financial support was received from any organization for the submitted work. Financial relationships: All authors have declared that they have no financial relationships at present or within the previous three years with any organizations that might have an interest in the submitted work. Other relationships: All authors have declared that there are no other relationships or activities that could appear to have influenced the submitted work.

\section{Acknowledgements}

This study was supported by a seed grant under the Center for Medical Countermeasures against Radiation Program (5 U19 A1 67769), National Institute of Allergy and Infectious Diseases and with Federal funds from the Biomedical Advanced Research and Development Authority, Office of the Assistant Secretary for Preparedness and Response, Office of the Secretary, Department of Health and Human Services, under Contract No. HHSO100201000005C.

\section{References}

1. Donnelly EH, Nemhauser JB, Smith JM, Kazzi ZN, Farfán EB, Chang AS, Naeem SF: Acute radiation syndrome: assessment and management. South Med J. 2010, 103:541-6.

2. Geara FB, Komaki R, Tucker SL, Travis EL, Cox JD: Factors influencing the development of lung fibrosis after chemoradiation for small cell carcinoma of the lung: evidence for inherent 
interindividual variation. Int J Radiat Oncol Biol Phys. 1998, 41:279-86.

3. Safwat A, Bentzen SM, Turesson I, Hendry JH: Deterministic rather than stochastic factors explain most of the variation in the expression of skin telangiectasia after radiotherapy. Int J Radiat Oncol Biol Phys. 2002, 52:198-204.

4. Travis EL: Genetic susceptibility to late normal tissue injury . Semin Radiat Oncol. 2007, $17: 149-55$.

5. Tichelli A, Rovó A, Gratwohl A: Late pulmonary, cardiovascular, and renal complications after hematopoietic stem cell transplantation and recommended screening practices. Hematology Am Soc Hematol Educ Program. 2008, 125-33. 10.1182/asheducation-2008.1.125

6. DiCarlo AL, Maher C, Hick JL, Hanfling D, Dainiak N, Chao N, Bader JL, Coleman CN, Weinstock DM: Radiation injury after a nuclear detonation: medical consequences and the need for scarce resources allocation. Disaster Med Public Health Prep. 2011, 5:32-44.

7. Folta-Stogniew E, Williams KR: Determination of molecular masses of proteins in solution: Implementation of an HPLC size exclusion chromatography and laser light scattering service in a core laboratory. J Biomol Tech. 1999, 10:51-63.

8. Gaasterland DE, Pederson JE, MacLellan HM, Reddy VN: Rhesus monkey aqueous humor composition and a primate ocular perfusate. Invest Ophthalmol Vis Sci. 1979, 18:1139-50.

9. Bill A: The blood-aqueous barrier. Trans Ophthalmol Soc UK. 1986, 105:149-55.

10. Worgul BV, Bito LZ, Merriam GR: Intraocular inflammation produced by X-irradiation of the rabbit eye. Exp Eye Res. 1977, 25:53-61.

11. Bito LZ, Klein EM: The unique sensitivity of the rabbit eye to x-ray-induced ocular inflammation. Exp Eye Res. 1981, 33:403-12.

12. Grabner G, Zehetbauer G, Bettelheim H, Hönigsmann C, Dorda W: The blood-aqueous barrier and its permeability for proteins of different molecular weight. Albrecht Von Graefes Arch Klin Exp Ophthalmol. 1978, 207:137-48.

13. Murray PI, Hoekzema R, Luyendijk L, Konings S, Kijlstra A: Analysis of aqueous humor immunoglobulin $\mathrm{G}$ in uveitis by enzyme-linked immunosorbent assay, isoelectric focusing, and immunoblotting. Invest Ophthalmol Vis Sci. 1990, 31:2129-35.

14. Lelie HL, Bui P, Tan C, Souda P, Whitelegge JP, McBride W, Down JD, Menon N: A proteomics approach towards identifying candidate biomarkers of ionizing radiation exposure. Proceedings of the 58th Annual Meeting of the Radiation Research Society. Radiation Research Society, San Juan, Puerto Rico; September 30 - October 3, 2012.

15. Menon N, Down JD, Tan CC, Bui P: Ionizing radiation biodosimetry through non-invasive ocular monitoring. The Medical Basis for Radiation-Accident Preparedness. A. Wiley, S. Sugarman, F. M. O’Hara, and D. Christensen (ed): Parthenon, New York; in press.

16. Krishnan L, Krishnan EC, Jewell WR: Immediate effect of irradiation on microvasculature. Int J Radiat Oncol Biol Phys. 1988, 15:147-50.

17. Sassen A, Reuter AM, Kennes F: Concentration of serum albumin in vascular and extravascular tissue pools of the mouse after x-irradiation. Radiat Res. 1969, 38:475-82.

18. Sharma M, Sharma R, Ge XL, Fish BL, McCarthy ET, Savin VJ, Cohen EP, Moulder JE: Early detection of radiation-induced glomerular injury by albumin permeability assay. Radiat Res. 2001, 155:474-80. 